\title{
Mumbai 2021 Call for Action Addressing the Need to Incorporate 'Nurturing Care for Early Childhood Development' in Pediatric Office Practice
}

\author{
Piyush Gupta, ${ }^{1}$ GV Basavaraja, ${ }^{2}$ Ranjan Pejaver, ${ }^{3}$ Dinesh Tomar, ${ }^{4}$ Alpesh Gandhi ${ }^{5}$ and Jaydeep Tank ${ }^{6}$ \\ ${ }^{1}$ President and ${ }^{2}$ Hon. Secretary General, Indian Academy of Pediatrics; ${ }^{3}$ President and ${ }^{4}$ Hon. Secretary General, \\ National Neonatology Forum (NNF); and ${ }^{5}$ President and ${ }^{6}$ Secretary, The Federation of Obstetrics and Gynaecological \\ Societies of India (FOGSI)
}

W e, the members of Indian Academy of Pediatrics (IAP) participating in Mumbai PEDICON 2021 in collaboration with National Neonatology Forum (NNF) and the Federation of Obstetric and Gynaecological Societies of India (FOGSI); supported by the World Health Organization (WHO) and United Nations Children's Fund (UNICEF), are committed to adopt all the components of the WHO/UNICEF Framework for Nurturing Care for Early Child Development (NC-ECD) in pediatric practice. In continuity with the IAP Consensus Statement on Early Childhood Development 2020 [1], we commit ourselves and our team members to provide an optimal healthy, safe, enabling, and nurturing environment for all children from birth till three years of age.

\section{Nurturing Care for Early Childhood Development Protects the Human Capital of the Country}

Every child has the right to a standard of living that is adequate for physical, mental, spiritual, moral, and social development. As pediatricians, we must strive to ensure that all children are able to attain their maximal growth and developmental potential. This is especially important in the first three years of life, a critical period in which the foundation for good health as well as academic, behavioral, socio-and emotional competencies are laid. Providing such an environment will promote good health, alleviate non-communicable diseases in adulthood, and enhance educational, professional, and economic potential of the future citizens on our country.

\section{Threats to Early Childhood Development}

We note with due concern that a large cohort of Indian children fail to attain their growth and developmental potential due to multiple risk factors like preventable health conditions, poor nutritional status, exposure to an unsafe environment, poverty, and lack of a conducive family environment.

\section{Moving Ahead}

We recognize that pediatric care should include the promotive, preventive, curative and rehabilitation services to addresses the holistic health needs of children starting from birth, as a universal approach for all children as well as for children at risk of poor development or children with additional needs. We move towards making a paradigm shift in our approach to pediatric practice that is focused on improving survival and decreasing morbidity, to 'Survive, Thrive and Transform' in alignment with the Global Strategy for Women's, Children's and Adolescents' Health, 2016-30 [2].

\section{THE PLEDGE}

We the members of the Indian Academy of Pediatrics (IAP), National Neonatology Forum (NNF), and The Federation of Obstetric and Gynaecological Societies of India (FOGSI), with support from our partners WHO, and UNICEF, do solemnly pledge to ensure that all the five components of NC-ECD (Good Health, Adequate Nutrition, Safety and Security, Responsive parenting, and Opportunities for Early Learning) are incorporated in the practice of our members, making incremental progress over the next three years (2021-2023) and sustaining the gains. To achieve this goal, we recommend the following actions for nurturing care that will be nation-wide, culturally sensitive, evidence based, and integrated with our existing practice.

\section{Action 1: Change Knowledge and Perception of Member Pediatricians}

- Sensitise IAP members on domains of Nurturing Care Framework through various IAP platforms and journals;

- Hold consultative meetings with the Government and other major stakeholders to mobilise support; and 
- Develop a Position Paper in continuity with the IAP Consensus statement on ECD 2020

\section{Action 2: Change Attitudes and Practices of Our Members}

- Undertake nationwide capacity building by National, Zonal, State and District level training workshops to attain competency in communication, counseling and imparting knowledge and skills on nurturing care to parents and caregivers, in, practicing a uniform system of well child visits in children less than 3 years by developing appropriate resource materials for pediatricians, and supporting mother's own health and mental wellbeing.

- Strive to make our facilities ECD compliant though innovative approaches.

\section{Action 3: Change Perceptions and Practices of Parents}

- Counsel and teach parents activities that promote good health, adequate nutrition, safety and security, responsive caregiving, and early learning, for their children and for their own wellbeing by:

- Developing resource material for parents on ECD.

- Display and dissemination of parent resource material.

- Capacity building of parents by individual and group counseling.

- Developing mobile applications and linking to the existing systems, where feasible.
Action 4: Change Perceptions and Practices of Medical Students and Allied Professionals

- Pre-service capacity building by proposing modification in undergraduate and postgraduate training curriculum.

- In-service capacity building of medical, nursing and paramedical staff by training workshops.

\section{Action 5: Documentation for Knowledge Management}

- Monitor progress, document, share experiences and disseminate good practices on the finalized ECD model. Evidence generation and measuring progress can further support the strategy.

We believe that this Mumbai 'Call for Action' will ensure improvement in outcomes related to child health, growth, and development, and that we will move one step forward towards attaining 2030 Sustainable Developmental Goals. Not even one child should be left behind.

(Signed on $7^{\text {th }}$ February, 2021 at Mumbai)

\section{REFERENCES}

1. Bharadva K, Shastri D, Gaonkar N, et al. Consensus Statement of Indian Academy of Pediatrics on Early Childhood Development. Indian Pediatr. 2020;57: 834-41.

2. World Health Organization. The Global Strategy for Women's, Children's and Adolescents' Health (20162030). Survive, Thrive, Transform. Accessed 20 February, 2021. Available from: www.who.int/life-course/partners/ global-strategy/en/ 